\title{
Editorial \\ Diversidad sexual y movimientos sociales
}

Felipe Caro Romero*

$\mathrm{E}$ n la mañana del 29 de mayo de 2020, en Bogotá, Alejandra Monocuco falleció al no recibir atención médica adecuada, después de que se había solicitado ayuda a causa de un fuerte dolor en el pecho. Alejandra era una mujer trans que vivía con el virus de la inmunodeficiencia humana (VIH), y a causa de los prejuicios que esto acarreaba el personal médico de emergencia se rehusó a atenderla. El 4 de julio del mismo año fue asesinado Mateo López Mejía, un hombre trans, líder comunitario del municipio de Circasia, Quindío. A pesar de la dolorosa situación, muchos medios de comunicación se rehusaron a llamar a Mateo por su propio nombre, identificándolo en femenino con el nombre que le fue asignado al nacer y no con el que él escogió. Unas semanas más tarde, el 30 de julio, en Sincelejo (Sucre), un joven gay de 17 años fue atacado y perdió un brazo. ¿La razón? estaba cansado de la homofobia constante que sufría en su barrio y decidió enfrentarse a su agresor, este le respondió con machete en mano. Un par de meses después, el 24 de septiembre, en un retén militar en Miranda, Cauca, fue asesinada por un soldado Juliana Giraldo, una mujer trans; el hecho se conoció después de que su pareja denunciara el crimen en un emotivo video compartido masivamente en redes sociales. Con este asesinato también se acabó una historia de amor que muchas personas considerarían improbable, ya que son pocos quienes asumen de manera abierta y honesta sus relaciones con personas trans.

Estos cuatro casos son un ejemplo de la difícil situación que viven las personas que se salen de la norma heterosexual en Colombia. Al hacer referencia a la norma heterosexual, no nos referimos a la orientación

* Doctorando en la Katholische Universität Eichstätt-Ingodstadt.

Correo electrónico: felipe.caroromero@ku.de 
sexual, sino a un sistema (y la sociedad) que perpetúa una diferenciación binaria de los cuerpos entre pasivos (femeninos) y activos (masculinos), a los cuales se les impone constantemente una serie de expectativas y se les exigen comportamientos a través de numerosas instituciones. El propósito de este dossier es tender las dinámicas del movimiento que interpela directamente a este sistema: el movimiento por la diversidad sexual.

Históricamente se puede rastrear el origen de este movimiento en América Latina a finales de la década de los sesenta, cuando se dieron las primeras movilizaciones en torno a la consigna de la liberación sexual. Luego, con la epidemia del VIH/SIDA a mediados de la década de los ochenta, la perspectiva radical dio paso a una búsqueda de apoyo estatal en medio de la crisis de salud pública. El nuevo milenio trajo consigo un cambio en la mayoría de la región, con la apertura democrática de algunos países que salían de dictaduras y otros que adelantaron reformas constitucionales; esto consolidó una perspectiva reformista dentro del movimiento que empezó a exigir a los diferentes Estados garantías para el buen vivir, incluyendo derechos patrimoniales, de matrimonio y adopción. Sin embargo, desde el inicio de la década de 2010 estamos viviendo una nueva etapa caracterizada por la reacción negativa que distintos sectores conservadores han tenido frente a los diversos logros que el movimiento ha conquistado en los últimos cincuenta años. Esta reacción, aglutinada bajo la lucha contra la "ideología de género" ha marcado la pauta en debates nacionales en toda la región. ${ }^{1}$ De igual manera, este periodo se ha caracterizado por ser un momento de introspección crítica del movimiento, en el que se ha cuestionado tanto las implicaciones en un mundo globalizado de la lucha contra la heteronorma como la reproducción de estructuras de opresión y violencia dentro del mismo movimiento.

1 Colombia no es la excepción a esto. Solo basta recordar el rol de que dichos sectores tuvieron en las marchas por la familia del 10 de agosto de 2016 y en la campaña contra el plebiscito por la paz de octubre del mismo año. 
En esta coyuntura la revista Controversia ha decidido dedicar el número 215 a reflexionar sobre el movimiento por la diversidad sexual. Los artículos que encontrarán a continuación reflejan el estado no solo de las agendas investigativas en torno a dicha diversidad; también es posible evidenciar las discusiones que se están dando dentro de las organizaciones. Por lo tanto, lo que estas investigaciones permiten constatar es que lejos de ser un movimiento homogéneo y estático, constituye un abanico de posturas y debates en torno a diferentes aspectos de la lucha contra la heteronorma característicos de un momento particular.

Por un lado, tenemos un par de textos que abordan la experiencia trans. Tradicionalmente esta ha sido invisibilizada por el protagonismo masculino y cisgénero dentro del movimiento por la diversidad sexual. Sin embargo, en los últimos años un creciente número de organizaciones trans se han hecho escuchar a través de una contundente movilización, proponiendo una agenda de discusiones propia. Ambos artículos retoman algunos de estos debates. El texto de Alejandro Gómez y Lisset Betancur expone los retos que existen en el mundo del trabajo sexual para mujeres trans. Allí se analizan las implicaciones que una regulación de dicho trabajo tendría para una población en alto estado de vulnerabilidad. Por otra parte, el artículo de Maria Antonella Barone nos ofrece un balance bibliográfico sobre la gestación, el parto y el aborto en hombres trans, en que además se discuten no solo las diversas perspectivas que han surgido al respecto tanto en las ciencias médicas como en las sociales, sino también se denuncia la falta de información que aún existe sobre un tema que para muchas personas sigue siendo un tabú.

Otro grupo de artículos corresponde a posiciones en torno a la relación entre la diversidad sexual y la negritud. Esta también es una perspectiva que ha crecido dentro del movimiento, junto a la creciente visibilización y apoyo de las corrientes anticoloniales y negras del feminismo, un aliado histórico de la diversidad sexual. El estudio de Angélica Galvis, Jesica Gómez, Linda Orcasita y Juan Rueda explora los procesos de conciliación entre la orientación sexual diversa en familias afro-colombianas, 
enfatizando en la importancia de reconocer un estado triple de discriminación (racial, social y de género). Por otra parte, el texto de Vinícius Zanoli es un análisis de una organización negra LGBTI de Campiñas, Brasil. Allí se discute como a lo largo de sus más de veinte años de trayectoria se puede observar el valor de una perspectiva interseccional desarrollada a través del trabajo social. Ambos artículos insisten en que es necesario incorporar al análisis del movimiento por la diversidad sexual un marco que reconozca los procesos de racialización, y la marginalización que estos implican. De lo contrario se perpetuará dentro del movimiento la violencia que está presente en el resto de la sociedad.

Estos dos grandes temas han sido debatidos recientemente en muchas partes del mundo. Tanto es así que la tradicional bandera de arcoíris, símbolo por excelencia del movimiento ${ }^{2}$ ha sido modificada para incluir en el costado izquierdo un triángulo con franjas que referencien tanto a las comunidades racializadas (negra y marrón), como a las personas trans (azul, blanca y rosado). En esto es posible registrar una relación constante entre el activismo político y la investigación académica, que no debe pasar desapercibida.

Los dos últimos textos del eje temático del dossier se presentan como reflexiones críticas sobre elementos centrales asociados al movimiento. Por un lado, el trabajo de Thierry Maire invita a pensar en los procesos de construcción de tradiciones a través del análisis de la marcha del orgullo en El Salvador. Allí se confrontan los relatos construidos sobre el origen de la tradición en el país contrastando una perspectiva nacional, reconstruida a través de investigación cualitativa, con la visión tradicional asociada al difusionismo estadounidense de la fecha. Este artículo resulta particularmente sugestivo en el contexto de publicación de esta

2 Comisionada por Harvey Milk al artista Gilbert Baker para la marcha en conmemoración de los disturbios de Stonewal, de 1978, en San Francisco. Desde 1990 su popularidad como el símbolo más representativo del movimiento se ha consolidado en todo el mundo. 
revista, ya que 2020 ha sido un año en el cual la mayoría de marchas conmemorativas de los disturbios de Stonewall que dieron origen a las marchas del Orgullo (Prides en inglés) se cancelaron. Por otro lado, Walter Bustamante nos ofrece una crítica a la mismísima noción de diversidad sexual, buscando el valor de la construcción de una identidad en un movimiento que lucha contra la heteronorma. En este artículo se retoma una discusión interna del movimiento respecto a su identidad y cuestiona cómo esta idea de diversidad ha jugado un rol tanto de potencializador del cambio como de restricción de este.

En este número también contamos con la sección de tema libre. Allí encontramos el texto de Juan Camilo Pantoja y Girlandey Sandoval, quienes estudian el rechazo que un sector conservador mostró en 1975 al nombramiento de Dora Luz Campo de Botero como gobernadora de Risaralda, por el hecho de haberse divorciado y vuelto a casar por lo civil. Finalmente, el trabajo de Kristina Dietz analiza el uso de narrativas para entender como los reclamos en los conflictos por minería y extracción petrolera están siendo contrarrestados. Ambos artículos son aportes novedosos a sus respectivos campos de estudio.

Esperamos que con esta entrega de Controversia se continúe una conversación cada vez más grande sobre los estudios del movimiento por la diversidad sexual en Colombia (y también en América Latina). El esfuerzo conjunto tanto de escritores como de editores y de pares revisores en esta revista representa un ejercicio de colaboración académica que ojalá se pueda seguir replicando, de modo cada vez más amplio y diverso. Solo a través de un diálogo constante y horizontal entre academia y política podremos construir conocimiento que nos permita transformar nuestra realidad. 